\title{
ANÁLISE DE CONSERVAÇÃO DO PATRIMÔNIO EDIFICADO: UM ESTUDO DE CASO NA IGREJA DA MADRE DE DEUS, RECIFE-PE
}

\author{
Clara Diana Figueirôa Santos ${ }^{i}$ \\ Kellen Larissa do Nascimentoii \\ Dayse Oliveira de Carvalho ${ }^{\mathrm{iii}}$ \\ Henry Sócrates Lavalle Sullasiv \\ Fernando Antônio Guerra e Souzav
}

'Doutoranda do Programa de PósGraduação em Arqueologia - UFPE clara.ufpe@gmail.com

iiGraduanda do Departamento de Arqueologia - UFPE

larissa8_@hotmail.com

iiiMestranda do Programa de PósGraduação em Arqueologia - UFPE dayse_carvalho1@hotmail.com iv Professor do Programa de PósGraduação em Arqueologia - UFPE henry.lavalle@ufpe.br

vProfessor do Departamento de Arqueologia - UFPE

arteculturaexpressao@hotmail.com
Abstract: The Madre de Deus Church is a landmark for the history of architecture, it is located in downtown Recife, Pernambuco. With unique pieces and styles, the church is an invitation to understand the historical religious and social contexts that makes up Pernambuco society from the 16th century to the present day. This work presents a historical and architectural survey of this Church, as well as the record of damages and agents observed which originated the deterioration and degradation of this Cultural Heritage. Some emergency solutions based on the data obtained during a visit from 2013 to 2019 were proposed.

Key Words: Madre de Deus Church, Recife, Cultural Heritage, Deterioration, Degradation. 


\section{Introdução}

O conceito de conservação está voltado a todas as ações que tenham como objetivo a salvaguarda do patrimônio cultural, assegurando sua acessibilidade às gerações atuais e futuras. A conservação compreende a conservação preventiva, a conservação curativa e a restauração, bem como todas estas medidas deverão respeitar o significado e as propriedades físicas do bem cultural em questão (Silva, Figueiredo Júnior e Silva, 2016).

O principal objetivo de um diagnóstico de conservação é avaliar suas necessidades de manutenção, identificando e definindo prioridades relativas a situações problemáticas; evidenciar casos de manutenção e gestão; ofertar soluções técnicas sustentáveis e apropriadas sempre que necessário, além de revelar vulnerabilidade e clima local (Zolczak, 2013).

É indubitável que os monumentos sofrem as consequências das condições atmosféricas e dos diferentes usos sociais ao longo dos tempos. O homem teve, desde sempre, sentido a necessidade de fazer perdurar todos os objetos que fossem úteis às suas necessidades, reparando aquilo que tivesse alguma função específica. O prioritário não era preservar testemunhos históricos, mas reparar algo que deixou de exercer as funções para a qual foi concebido, se necessário alterando-o.

Neste contexto, originalmente um edifício não é compreendido como um bem que possui valor histórico ou cultural, mas como um bem útil ou que representa algo a uma sociedade (Luso, Lourenço e Almeida, 2004). É neste sentido que é visto e discutido aqui o atual valor da edificação em estudo, uma vez que para ser conservada é necessária de ser vista como algo de valor no uso e na memória da sociedade.

O objeto em questão é a Igreja da Madre de Deus, situada no centro da cidade do Recife, um elemento de importância no desenvolvimento urbano, sociocultural, paisagístico, histórico e religioso da cidade. Suas relações com as faces sociais e ambientais diretamente relacionadas a este trabalho, revelam um baixo grau de conservação e valor comunitário. Na busca de entender melhor as condições de conservação dessa edificação, foram abordadas as questões administrativas, sociais e históricas do monumento e discutidas, à luz do diagnóstico de conservação obtido durante as visitas técnicas.

Trabalhos com abordagem similar a este são comuns, como é o caso de um estudo na Igreja de Nossa Senhora da Assunção, antiga Sé de Elvas, Alentejo-PT, no qual foram realizadas 
pesquisas historiográficas e levantado dados da conservação do monumento, com foco no estudo do comportamento das argamassas (Salema, Proença e Cardoso, 2008).

Outros trabalhos de abordagem similar foram os estudos nas Igrejas de Minas Gerais-BR, nas Matrizes de Nossa Senhora da Conceição e de São José de Montes Claros, onde foi realizado um estudo minucioso do acervo histórico, cultural, bem como dos fatores e condicionantes do desgaste estrutural das edificações para a restauração delas. $O$ trabalho reconheceu que o patrimônio histórico do município sofreu forte descaracterização proveniente de reformas que alteraram inteiramente seu estilo arquitetônico e reconheceu, também que, com o intuito de minimizar essa descaracterização, um novo projeto necessitava de ser elaborado de modo a restaurar o patrimônio depreciado (Prates, et al., 2015).

A igreja da Madre de Deus é um monumento nacional barroco, edificado em 1720 e tombado como patrimônio histórico, desde 1938, pelo Instituto do Patrimônio Histórico e Artístico Nacional (IPHAN). Está localizada no bairro do Recife, na Rua Madre de Deus (figura 1). Suas coordenadas em UTM correspondem a: $293490.24 \mathrm{~m} / \mathrm{E}$ e $9108122.28 \mathrm{~m} / \mathrm{S}$, cujo Datum é o WGS 84.

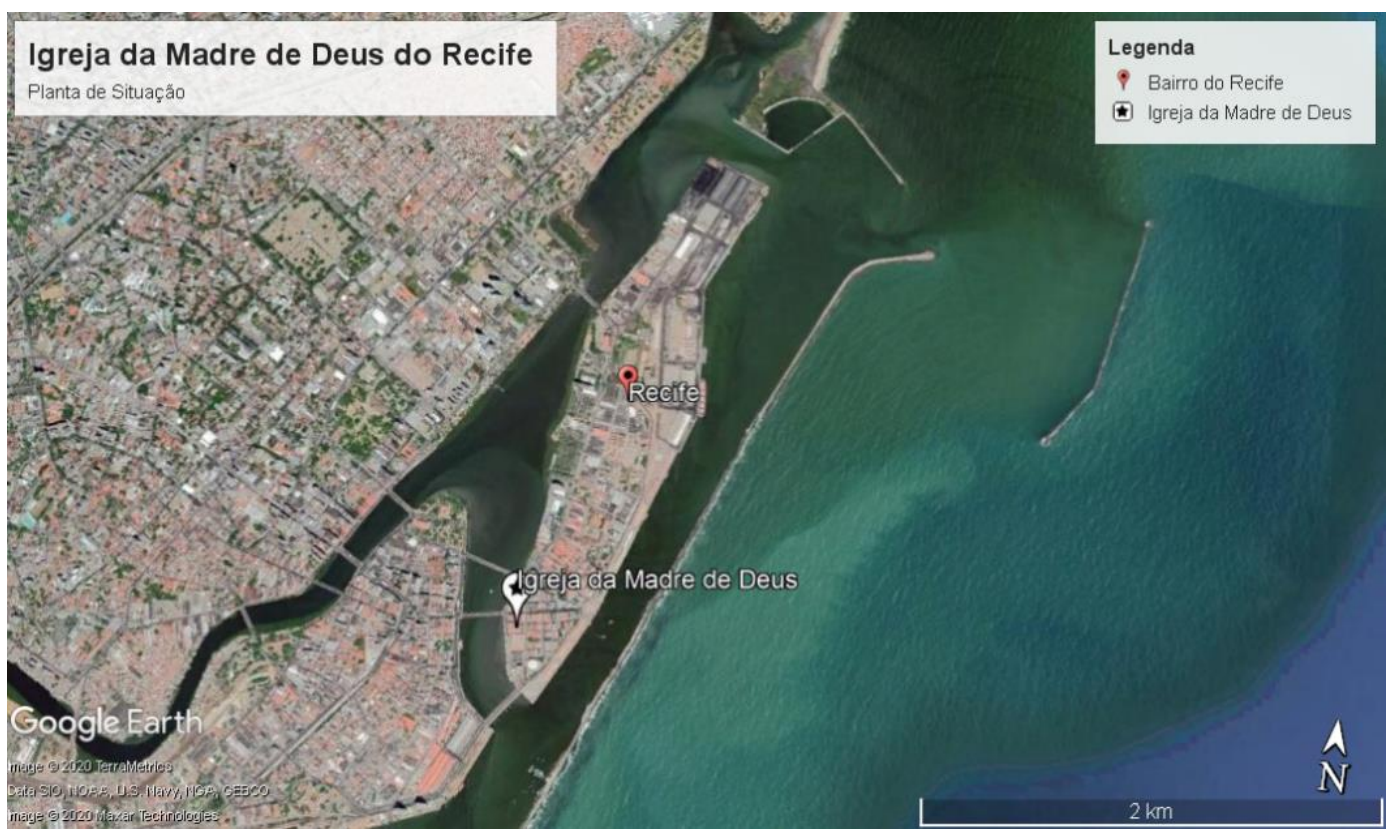

Figura 1: Planta de situação da Igreja Madre de Deus do Recife. Fonte: Google Earth, 2020

O edifício do convento foi construído ao lado da igreja, onde os padres promoviam cursos de Estudos Gerais, Filosofia e Teologia, bem como proviam os pobres de alimento, roupa, dinheiro e medicamentos. Em uma remodelação urbanística, a igreja foi separada do convento 
por uma rua aberta entre essas duas edificações, chamada atualmente de Alfândega, sendo, para isso, demolida parte do edifício do convento, o qual hoje corresponde ao Shopping Paço Alfândega, edificação de grande representatividade cultural do Recife, conforme figuras 2 e 3. A igreja e o convento pertenciam à Ordem dos Oratorianos de São Filipe de Néri, fundada sobre a invocação da Madre de Deus.

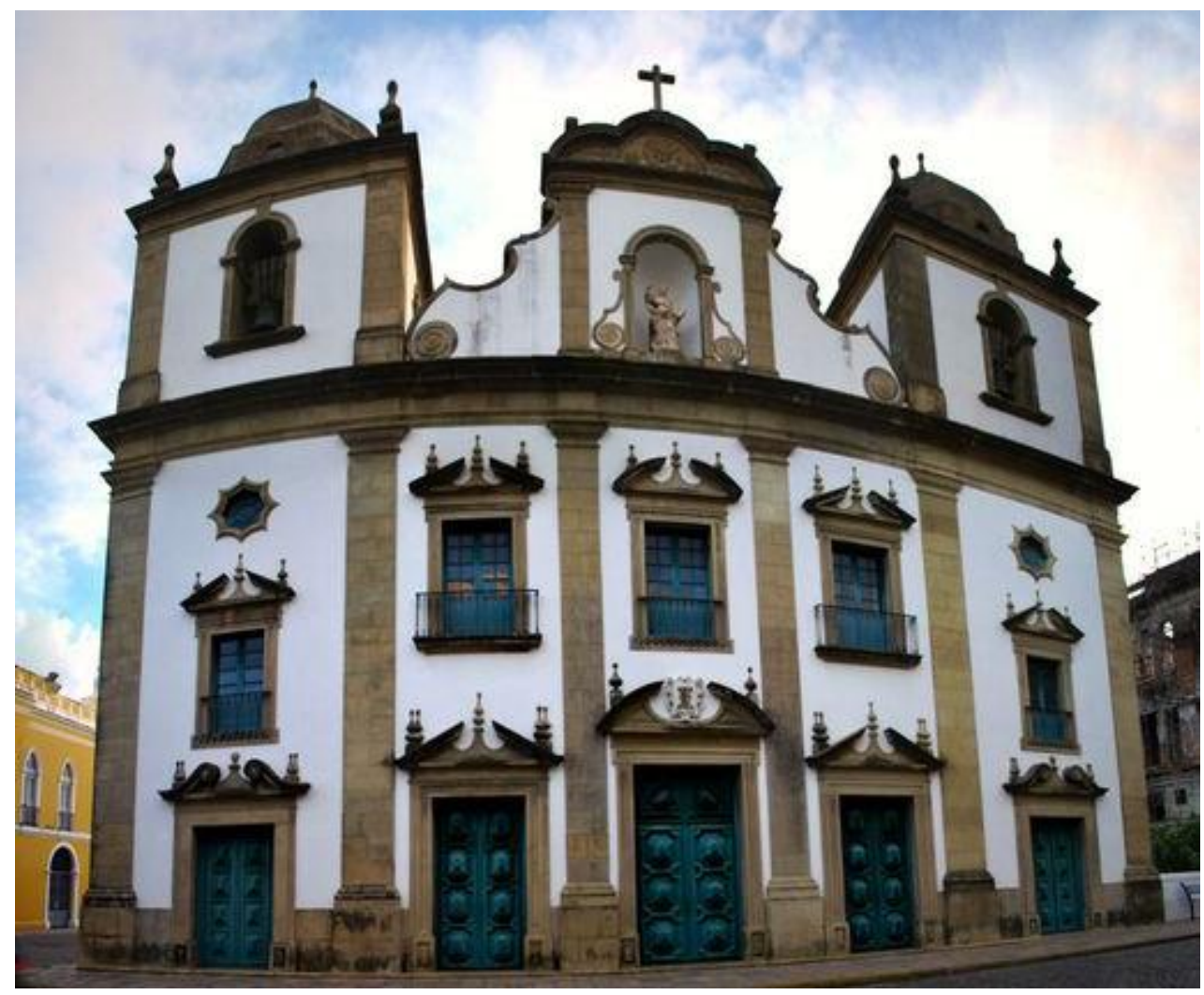

Figura 2: Frontispício da Igreja Madre de Deus do Recife. Fonte: Silvannir Jaques, $2014^{1}$

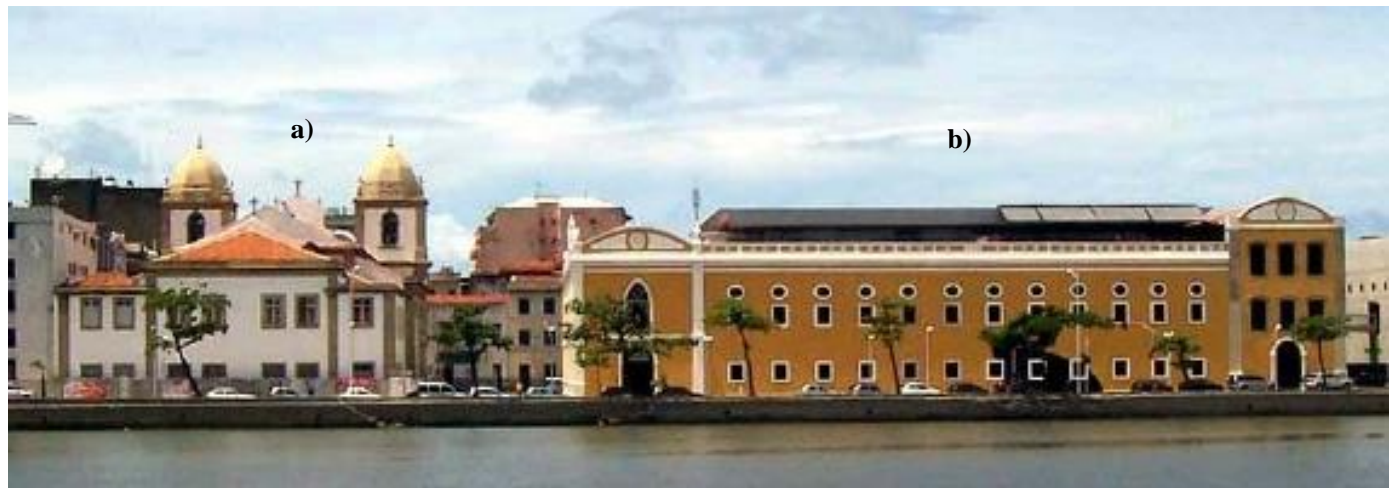

Figura 03: Fachadas posteriores (a) Igreja da Madre de Deus; (b) Convento, hoje Shopping Paço Alfândega. Fonte: Acervo pessoal, 2013.

${ }^{1}$ Disponível em: https://www.apontador.com.br/local/pe/recife/igrejas/C41442303251105119/igreja madre de deus.html 


\section{Contexto Histórico}

O terreno de sua construção foi doado pelo Senhor Coronel Antônio Fernandes de Matos, carta que se encontra no cartório José Cardoso Moreno, onde o mesmo ajudou com custos até o final da construção da igreja, com o único motivo de ter um lugar principal dentro da mesma para ser sepultado, onde também rezar-se-ia uma missa em sua homenagem todos os dias (Mello, 1994).

Em 1534, em Olinda, existia um convento da Ordem de São Filipe de Néri, fundado na época em que a capitania pernambucana participou do ciclo da cana-de-açúcar. Por volta do ano de 1650, plena época de catequização, os padres João Duarte do Sacramento e Bartolomeu de Quental, desejavam fundar em Pernambuco duas congregações do tipo Oratoriano. Dessa forma, em 1671, o padre João Victorio foi enviado a Roma para solicitar a autorização do Papa Clemente $\mathrm{X}$, onde ele sugeriu a criação de uma congregação que fosse semelhante à de São Felipe de Nery, originária da Itália. A sugestão foi aceita e passou a existir a Congregação dos Oratorianos de São Filipe de Néri de Portugal e Pernambuco (Mello, 1994).

Os padres oratorianos se instalaram inicialmente em um lugar retirado do centro de Recife tendo a casa de Santo Amaro como local de permanência. Posteriormente a comunidade muda-se de Santo amaro para Recife e a Casa antiga em recife serviria de repouso para os oratorianos. Com o passar do tempo e crescimento da congregação a casa de Recife foi ampliada e teve lugar a construção de um grande convento, ao qual se sumaria a igreja. A atual igreja de Madre de Deus teve seu início da construção em julho de 1706 (Simis, 2005).

No ano de 1688 o convento foi elevado à categoria de Casa Principal da Ordem, ficando a de Olinda destinada para férias e convalescência dos padres enfermos. Nele funcionava desde a sua fundação, um curso secundário de Filosofia e Teologia, como também cursos superiores de Geometria, Música, entre outros; as aulas também eram ministradas para os presidiários. Os oratorianos de São Filipe de Néri foram expulsos em 1678 por desavenças políticas governamentais. Um grupo se refugiou no interior do Nordeste, e outro foi para o estado de São Paulo. Tempos depois, os que sobreviveram, voltaram para Portugal (Simis, 2005).

Com o passar dos anos, o número de fiéis foi aumentando e logo surgiu a necessidade de amplificação da capela, cujo mentor foi o Padre João Duarte do Sacramento, pela invocação da Madre de Deus. Assim, em 1707, uma carta régia, concedeu subsídios aos padres que thes 
permitissem iniciar a construção. Para sua conclusão, em 1711 enviaram uma nova ajuda de cinco mil cruzados, outorgada por cinco anos, além do auxílio real que chegou em 1715 e, naquele mesmo ano, foi celebrada a primeira missa. Entretanto a igreja, em sua totalidade, só foi entregue ao culto no dia 24 de março de 1720, no dia de Ramos, tornando-se a Matriz do bairro do Recife (Mello, 1994).

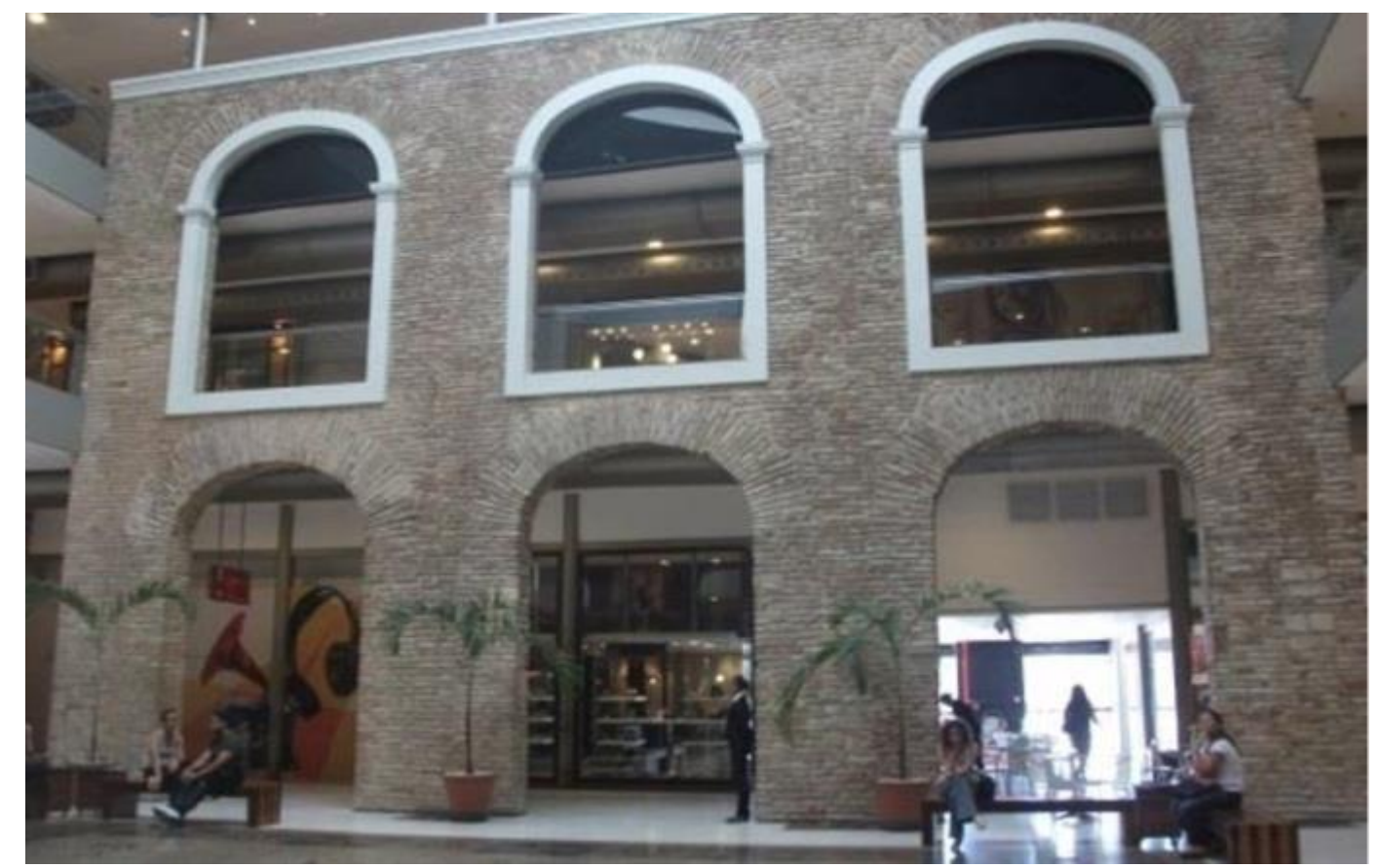

Figura 4: Vista interna da área interna central do atual Shopping Paço Alfandega, antigo Convento da Madre de Deus. Fonte: Acervo pessoal, 2013

Em dezembro de 1825, o edifício do convento foi confiscado pelo Aviso Imperial para instalação da Alfândega do Recife (figura 4). Em dezembro de 1830, a congregação de São Filipe de Néri foi extinta, de forma que o edifício da Igreja e outros imóveis foram incorporados a Fazenda Nacional passando, em 1835, a administração para a Irmandade de Sant'Ana. Além dessa irmandade, diversas outras se instalaram na igreja, ao longo dos anos. A Irmandade de Nossa Senhora Mãe dos Homens ficou nela abrigada, desde o 04 de dezembro de 1864 até o ano de 1866. Também a Igreja Madre de Deus inseriu objetos de outras igrejas, como a de Corpo Santo, devido a sua demolição em 1913, (Barbosa, 1983).

Posteriormente num incêndio causado por um curto-circuito na instalação elétrica, por ocasião de um casamento, em 21 de março de 1971, trouxe inúmeros danos principalmente ao acervo artístico da igreja ela teve sua capela-mor destruída pelas chamas e ocorreram danos irreparáveis (Menezes, 2007). Ela ficou bastante danificada, tendo sido queimadas as obras de 
talha do forro da cúpula e do altar-mor (figura 5). As chamas atingiram, também, os quadros que ornam as paredes laterais da capela-mor e várias imagens, dentre elas, as da Sagrada Família, de São Pedro Apóstolo, a de São Frei Pedro Gonsalves e o crucifixo denominado Bom Jesus das Portas, sendo as demais salvas do incêndio por pessoas que se encontravam no local.
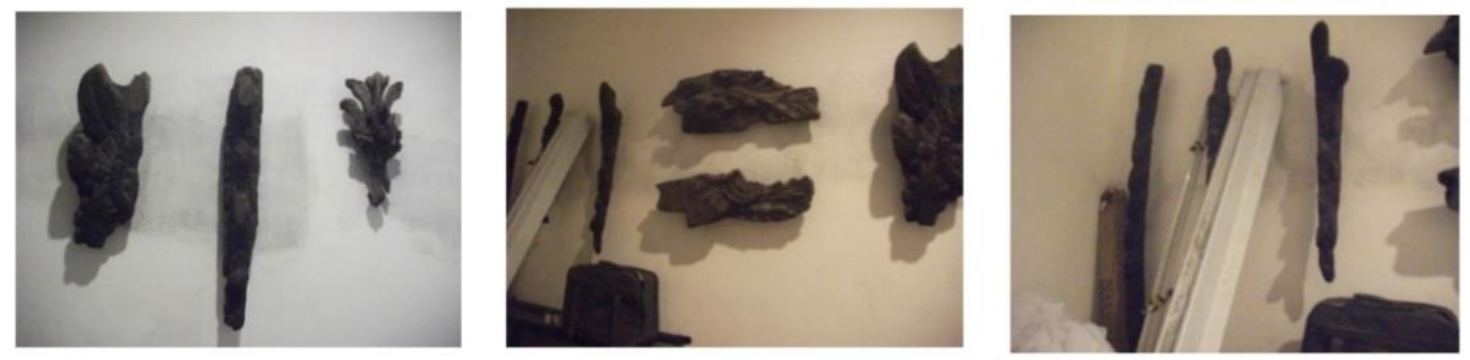

Figura 5: Peças carbonizadas do Capela-mor. Fonte: Acervo pessoal, 2013

Algumas peças foram salvas por mulheres que viviam no antigo hotel chamado Chanteclair, que também funcionava como bordel, elas notaram o incêndio e adentraram na igreja salvando parte do acervo. A restauração dos pontos críticos do incêndio só ocorreu quatro anos depois e duraram 13 anos de trabalho, o qual foi de grande complexidade devida à exuberância do barroco com sua riqueza ornamental. A igreja voltou a funcionar em suas atividades religiosas em 02 de junho de 1984 (Menezes, 2007)

\section{Contexto Arquitetônico}

A construção teve início em um modelo simples, de taipa, porém com o aumento do número de fiéis, ocorreu à necessidade de uma remodelação do tamanho e do desempenho dela. A igreja, após sua conclusão, no primeiro quartel do século XIX, apresentava uma única torre. Ao longo dos anos, sofreu novas modificações, tendo sido acrescentadas a outra torre, em 1931, ocultadas às cantarias, atualmente rebocadas com granitado (Smith, 1955).

A fachada principal (figura 6) é cortada verticalmente por duas pilastras centrais e quatro cunhais que delimitam as torres, que são rematadas superiormente por uma cornija. Acima dessa cornija, erguem-se os últimos andares das torres sineiras, que têm cobertura em forma de calota esférica, pouco alongada e, no centro, o frontão retangular com o nicho do padroeiro, encimado por uma cruz e pináculos (Smith, 1955).

No nível do pavimento térreo (figura 6), existem cinco portas de madeira, almofadadas, com vergas retas e frontões sincopados, adornados com pináculos. Sobre esses vãos, há cinco 
janelas envidraçadas, com balcões de ferro, com vergas retas e frontões sincopados, sendo que as situadas nas verticais das torres são encimadas por óculos redondos, envidraçados, com molduras em pedra. Os dois campanários apresentam vãos em arco com peitoris salientes (Smith, 1979)

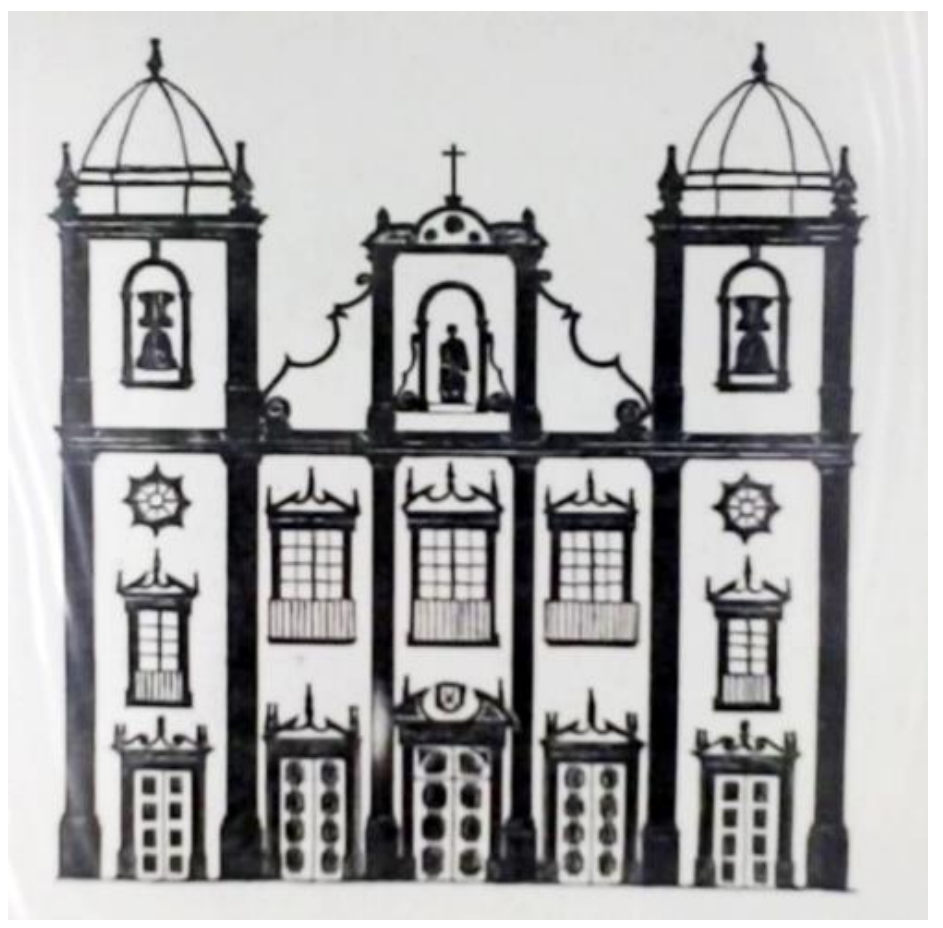

Figura 6: Representação da fachada principal. Fonte: Iphan, 1950.

Interiormente, a igreja é constituída por uma ampla nave com corredores laterais, conforme a figura 7 (a). Nela, existem três altares de cada lado e dois colaterais ao arco-cruzeiro, dois níveis de balcões, dois púlpitos, vários painéis a óleo sobre tela assinados por Henrique Mosar e Baltazar da Câmara, além de um coro alto, apoiado sobre dois grandes pilares de arenito, com as bases ornadas com losangos (Smith, 1979).

O teto é constituído por pequenas abóbadas cruzadas, ornadas de talha com motivos fitomórficos, onde aparecem algumas peças enegrecidas pelo incêndio, que foram aproveitadas e rodeadas por outras executadas posteriormente (figuras 7 (b) e 8). 


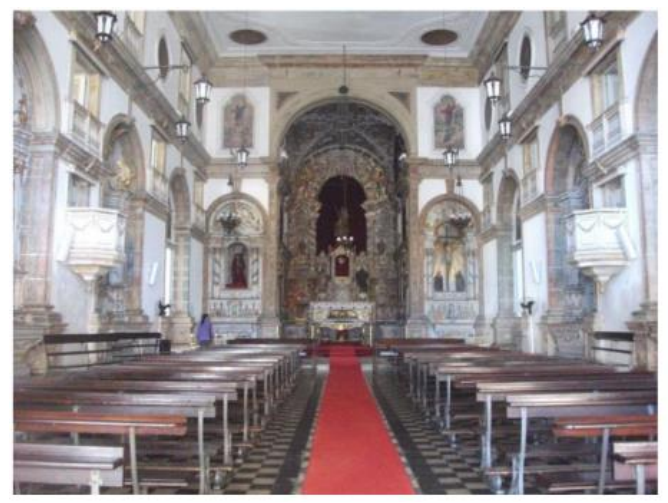

$\leftarrow$ a)

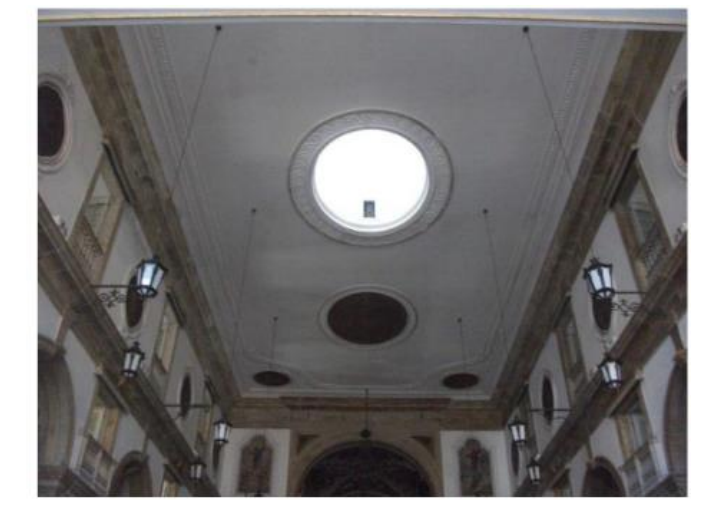

Figura 7: (a) Nave principal; (b) Detalhe do teto da igreja. Fonte: Acervo pessoal, 2014.

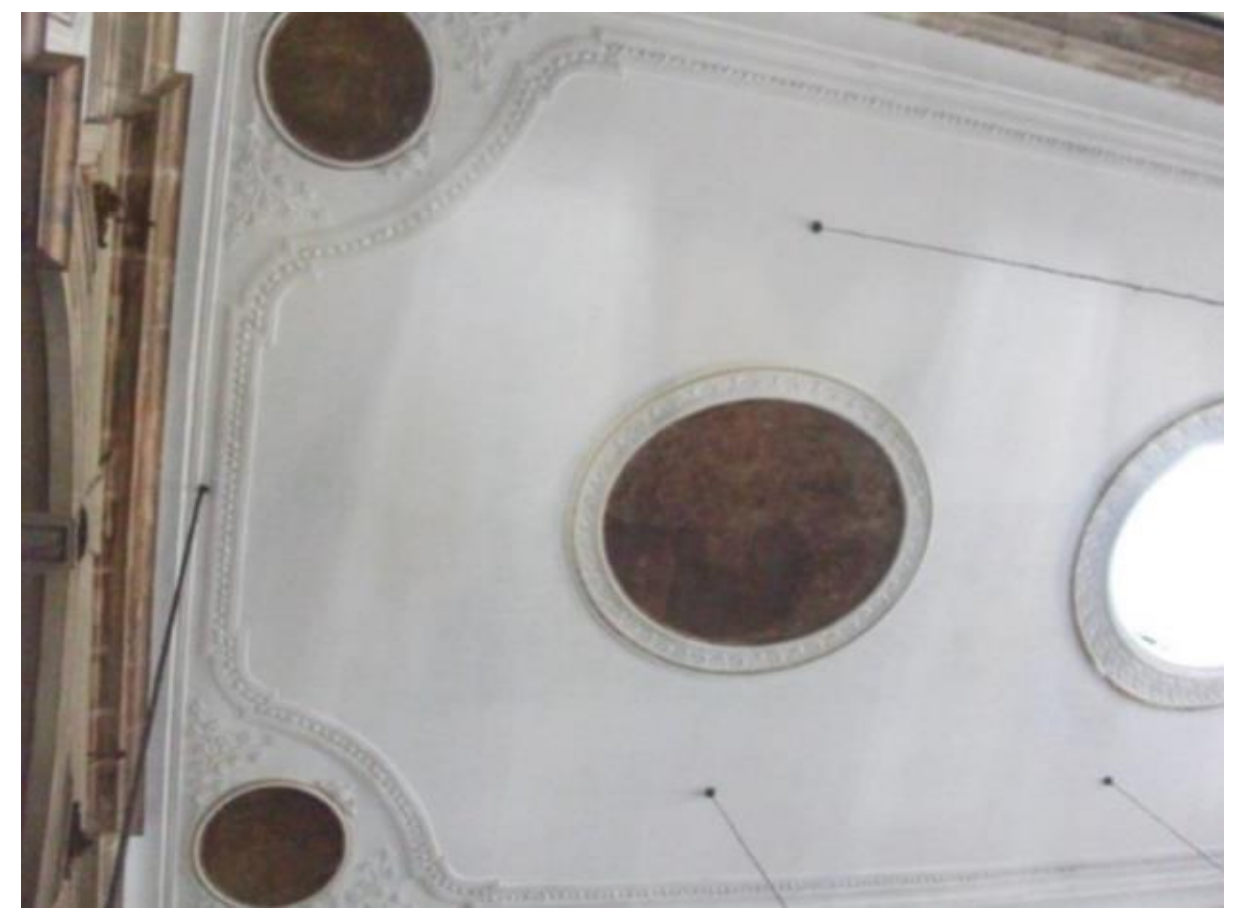

Figura 8: Pinturas do teto abstratas por conta do incêndio de 1970. Fonte: Acervo pessoal, 2013.

Os altares colaterais ao arco-cruzeiro apresentam retábulos com pintura antiga e denotam uma talha de transição do rocaille para o neoclássico nas suas colunas de fuste quase lisa, nos ornatos floridos e simples, embora no frontão se misturem ainda peças arquitetônicas cercando uma cartela fenestrada. O dourado é utilizado para avivar ornatos e o branco dá a nota dominante da cor (Bazain, 1993).

Os altares laterais seguem o estilo dos colaterais, com exceção daquele que abriga a imagem de São Francisco de Sales, que é de planta côncava, com colunas salomônicas, frontão com baldaquino ao gosto joanino, mas que se julga de construção posterior. As ilhargas da capelamor apresentam painéis a óleo sobre madeira, representando cenas do Novo Testamento, 
atribuídos a Sebastião Canuto da Silva, que foram queimados no incêndio; dois balcões em cada lado, com guarda-corpos com balaústres e talha dourada florida (Bazain, 1993).

O retábulo do altar-mor, embora queimado parcialmente e restaurado (figura 9), conserva os vestígios carbonizados e o aspecto suntuoso da talha joanina, com a sua planta côncava, onde se inserem pares de colunas salomônicas assentes sobre mísulas e atlantes. Tem na base uma mesa de altar, acessível por cinco degraus curvos, a partir do pavimento da capela, com o frontal aberto formando um nicho, onde é abrigada a imagem do Senhor Morto.

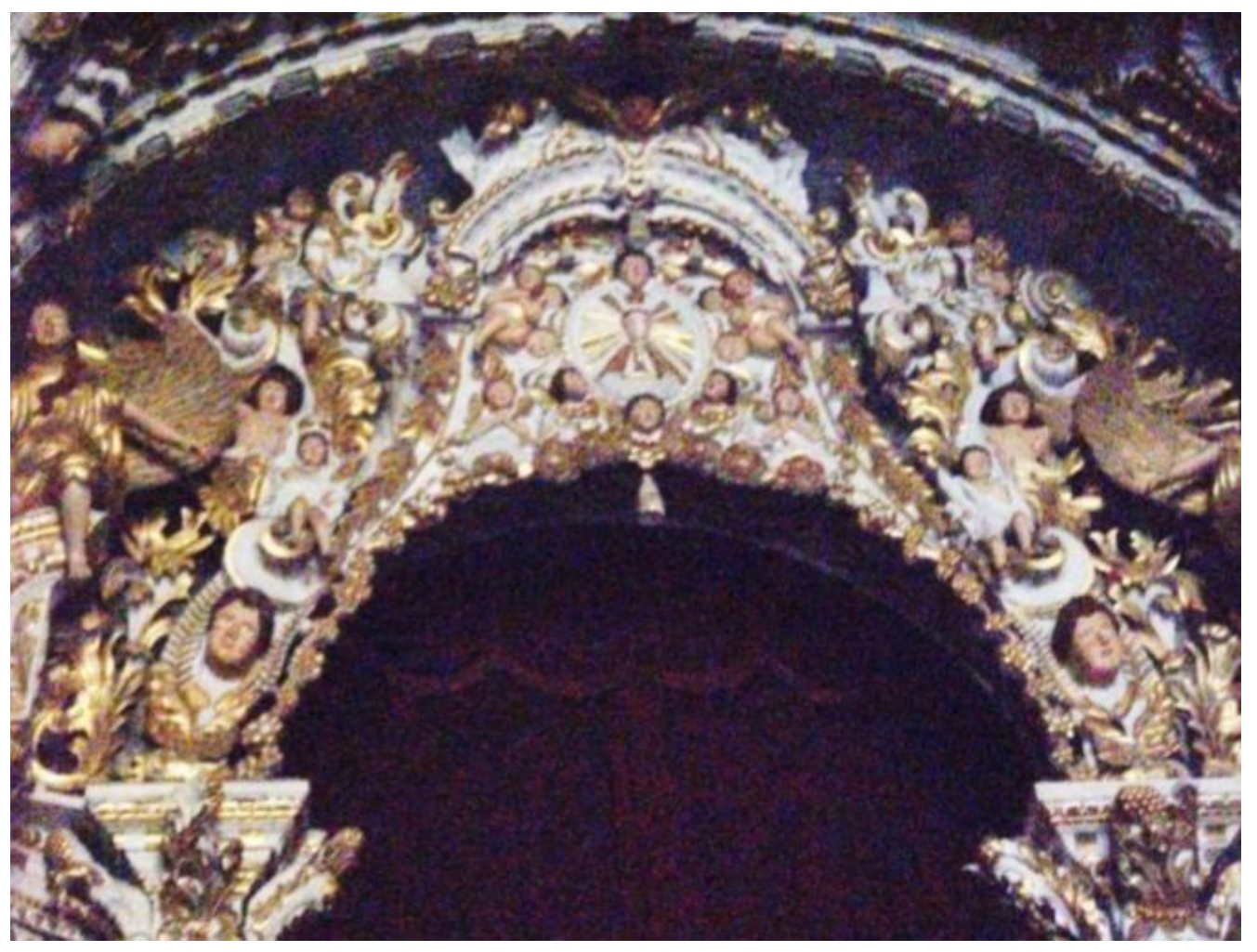

Figura 9: Detalhes da Capela-mor. Fonte: Acervo pessoal, 2013.

Aos lados do sacrário sobre mísulas estão às imagens de São Pedro Apóstolo e de São Pedro Gonsalves, padroeiro da igreja. A parte superior do retábulo é do tipo joanino. O trono foi destruído pelo incêndio e, em seu lugar, foi colocado um Cristo, em grande vulto, preso à parede de fundo do camarim.

A sacristia, que fica situada atrás da capela-mor, é um ambiente ricamente adornado. Possui um belo arcaz de jacarandá, com alçado formado por painéis entalhados e um oratório, em cedro; dois armários de amictos, também em jacarandá; um magnífico lavabo de mármore de Extremoz, e o teto de uma bonita composição de traçado ondulado com medalhões circulares, 
tendo os centros com figuras de anjos, o ambiente inclui peças de Manuel da Silva Amorim e do escultor João Pereira (1746).

A igreja Madre de Deus teve o frontispício cortado verticalmente por pilastras e limitando por cunhais, sendo a parte superior, construída pelo nicho e pelas torres, separada do corpo da fachada por uma grande cornija, moldurada e horizontal (Barbosa, 1983).

No macro ambiente da igreja é possível perceber o estilo Maneirista marcado pelos pequenos frontões sincopados dos vãos. Acima da cornija, erguem-se os últimos andares das torres sineiras, que têm cobertura em forma de calota esférica pouco alongada e, no centro, o frontão retangular com o nicho do padroeiro, encimado por uma cruz e pináculos.

À estrutura da igreja foi reconstruída e a sua restauração foi realizada pelo Iphan, em parceria com a Fundação de Apoio ao Desenvolvimento da Universidade Federal de Pernambuco (Fade) devido ao incêndio ocorrido em 21 de março de 1971.

Já a última intervenção de restauro foi promovida pelo Programa Monumenta, um programa federal executado pelo Ministério da Cultura do Brasil e patrocinado pelo Banco Iberoamericano de Desenvolvimento ( $\underline{B I D}$ ), que consiste na reforma e resgate do patrimônio cultural urbano em todo o Brasil. Em Pernambuco foi consequência de uma parceria entre a arquidiocese de Olinda e Recife, o Ministério da Cultura e Prefeitura do Recife, que contemplou a restauração de fachadas, telhados e entorno. A ação foi iniciada em 2002 e reabriu as portas no fim de outubro de 2006 (Zárate e Moreira, 2010).

\section{Diagnóstico de Conservação}

A pesquisa teve início em junho de 2013 , com prospeç̧ões no intuito do diagnóstico do estado de preservação da Igreja da Madre de Deus, do Recife. As descrições a seguir são dos anos de 2013, 2014, 2016 e 2019. Levando em conta a localização da igreja e seu contexto ambiental, foi possível identificar possíveis causas para os danos estruturais e biológicos identificados, além dos danos casuais administrativos identificados.

É comum a ocorrência de intempéries causadas pela temperatura do local e da umidade do ar (Rios V. G. et. al., 2018). Ao longo da pesquisa foi percebida a formação de micro e macro climas, como visto na galeria direita do segundo piso, onde uma infiltração de água ocasionou o aparecimento de fungos no piso de madeira, a qual está comprometida e por isso apresenta 
risco de desabamento. Em outros locais da mesma galeria e como nas escadarias que levam ao campanário, é facilmente visto formação de liquens (figura 10).

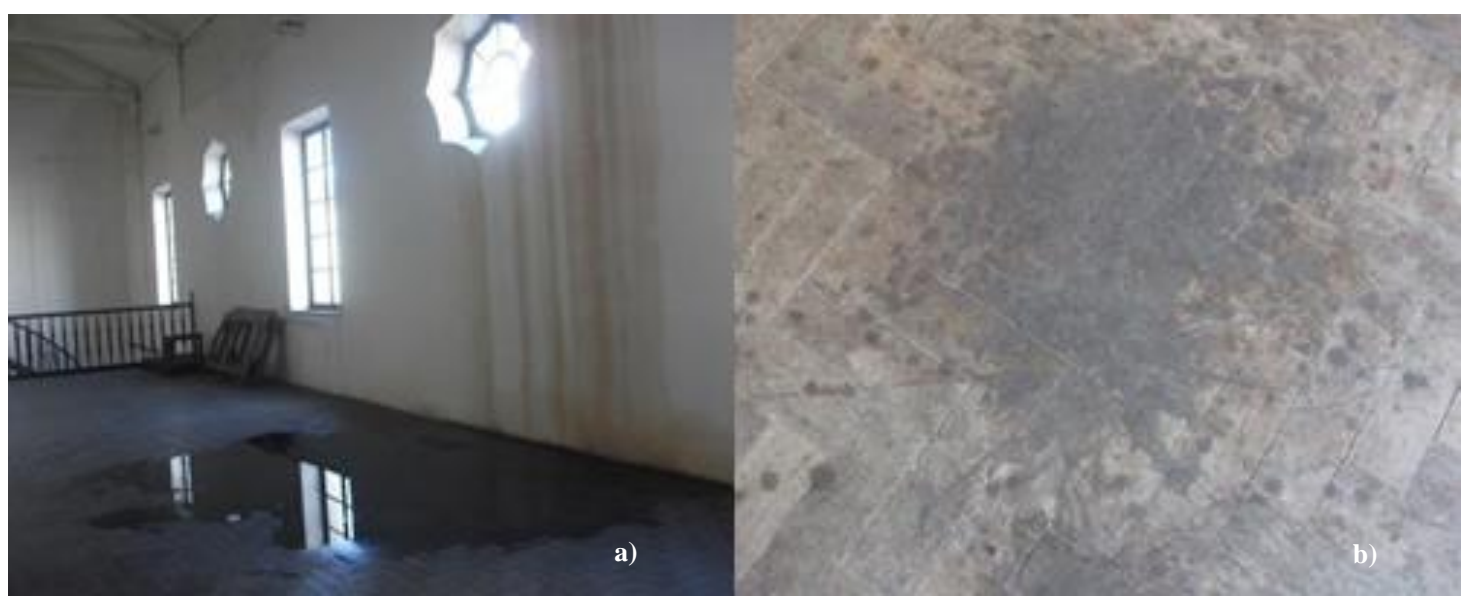

Figuras 10 (a e b): Acúmulo de água formado devido à inexistência de vidros nas janelas na ala superior; Presença de liquens no piso. Fonte: Acervo pessoal, 2013.

Como fatores bióticos foram encontrados cupins na estrutura de várias naves, exceto da principal, onde são realizados eventos; em móveis que estão localizados no corredor Oeste do primeiro andar, além de antigos armários de madeira que estão dispostos ao longo do corredor. Também foi evidenciada a presença de liquens no mesmo corredor ao longo de toda a parede e em manchas próximas ao teto, indicando grande concentração desse micro bioma, bem como uma infiltração encharca o piso de madeira provocando eflorescências e inviabilizando o uso do piso. Isso ocorre por conta das infiltrações que podem ser observadas também no corredor Leste do primeiro andar e do térreo, por conta da chuva e do emprego de materiais porosos na construção, como da presença ativa da capilaridade.

Foram registradas também placas soltas nos jazigos e rachaduras nas paredes da área cemitérial atual, as quais podem ser explicadas por um intenso tráfego de carros e veículos de grande porte na Rua da Madre de Deus, gerando sobrecarga em solos de alta capilaridade, como é o caso da área fluvial do bairro do Recife.

Nos campanários foi notado o acúmulo de fezes de animais (figura 11). Nos jazigos que ficam localizados em um cômodo atrás do altar-mor foi observada a presença de sujeira e de aranhas do gênero Loxosceles mais conhecida como "aranha-marrom", um espécime doméstico e venenoso. 


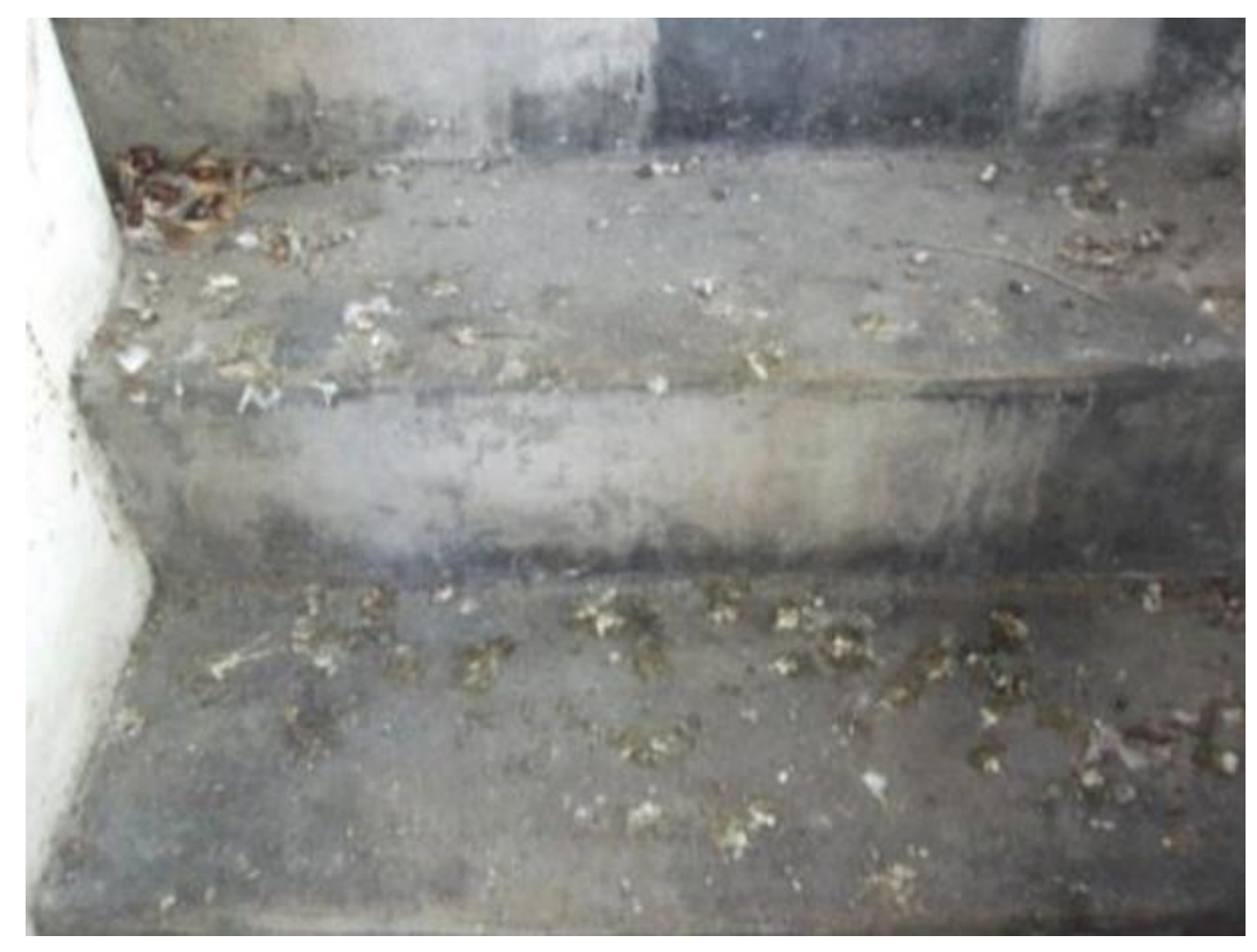

Figura 11: Presença de fezes na escadaria de acesso a torre dos sinos. Fonte: Acervo pessoal, 2013.

Quanto aos problemas estruturais, além do dano causado pelas infiltrações por cupins, as vigas de ferro da cúpula estão muito enferrujadas e algumas partidas, a estrutura do forro e outras vigas de madeira estão ressecadas e com a presença de cupins, outras estruturas metálicas também enferrujadas podem ser encontradas nos corredores Oeste e Leste do primeiro andar. Algumas partes da escadaria apresentaram degraus soltos.

Ainda foi possível perceber partes danificadas pelo incêndio, como a parte mais alta da cúpula e do altar-mor, o coroamento e o forro octogonal. Nos altares observa-se a presença de estátuas danificadas como, por exemplo, a única estátua nesta posição no Brasil da Santa Maria Egipcíaca.

Na sacristia têm-se um mobiliário extraordinário, como os armários de madeira raros do tipo pau-rosa escuro embutidos, são quatro unidades que decoram a sala, com alçados típicos em molduras quadradas e dois desenhos diferentes. Um tem vinte gavetas para amictos, quadradas, colocadas por cima de dois compridos gavetões que, por sua vez, se apoiam sobre o espaço do armário, fechado por duas portas ricamente trabalhadas; contudo agora há 
somente quinze gavetas para amictos na parte superior e os quatro compartilhamentos de baixo são inteiramente abertos, havendo um simples gavetão de fundo.

Cada campanário possui quatro sinos, alguns desses sinos vieram de Portugal e outros foram confeccionados em Pernambuco, porém, desses oito sinos, só funcionam dois, alguns dos que estão fora de funcionamento se encontram abandonados na sacristia ou em corredores (Menezes, 2007)

O projeto Monumenta visava nesta igreja proporcionar conhecimento patrimonial, que seria materializado por meio de vídeos e informes exibidos em uma sala do edifício, contando a história da igreja e do valor cultural que ela possui, também seria retratada em uma maquete a igreja como foi encontrada antes da restauração, para perceberem o quanto fora modificado, entretanto a sala destinada ao projeto está em desuso.

A escadaria que dá acesso ao primeiro andar continua sendo original e foi restaurada pelo projeto Monumenta. No primeiro pavimento, o lugar é conservado em partes, existem alguns móveis pelo corredor com acúmulo de água, danificando o piso de madeira, este acúmulo ocorre devido à ausência de vidros nas janelas.

As pinturas que não foram afetadas pelo incêndio também apresentaram desgaste com o acúmulo de poeira e opacidade devido ao atrito das partículas trazidas pelo vento até a camada pictórica. No mesmo local é evidente a depredação dos vitrais, principalmente o da cúpula que, quando chove ocorre o alagamento da nave principal.

Artefatos como as esculturas, pinturas; e ambientes como os altares, escadarias, salões e jazigos encontraram-se danificados pelo lixo e poeira (figura 12); um caso antiético com o patrimônio, com a memória mortuária e com a história. O zelo pelo patrimônio é obrigação de todos e assegurado pela Decreto Lei $\mathrm{n}^{\circ} 25$, de 30 de novembro de 1937, da Constituição Brasileira. 


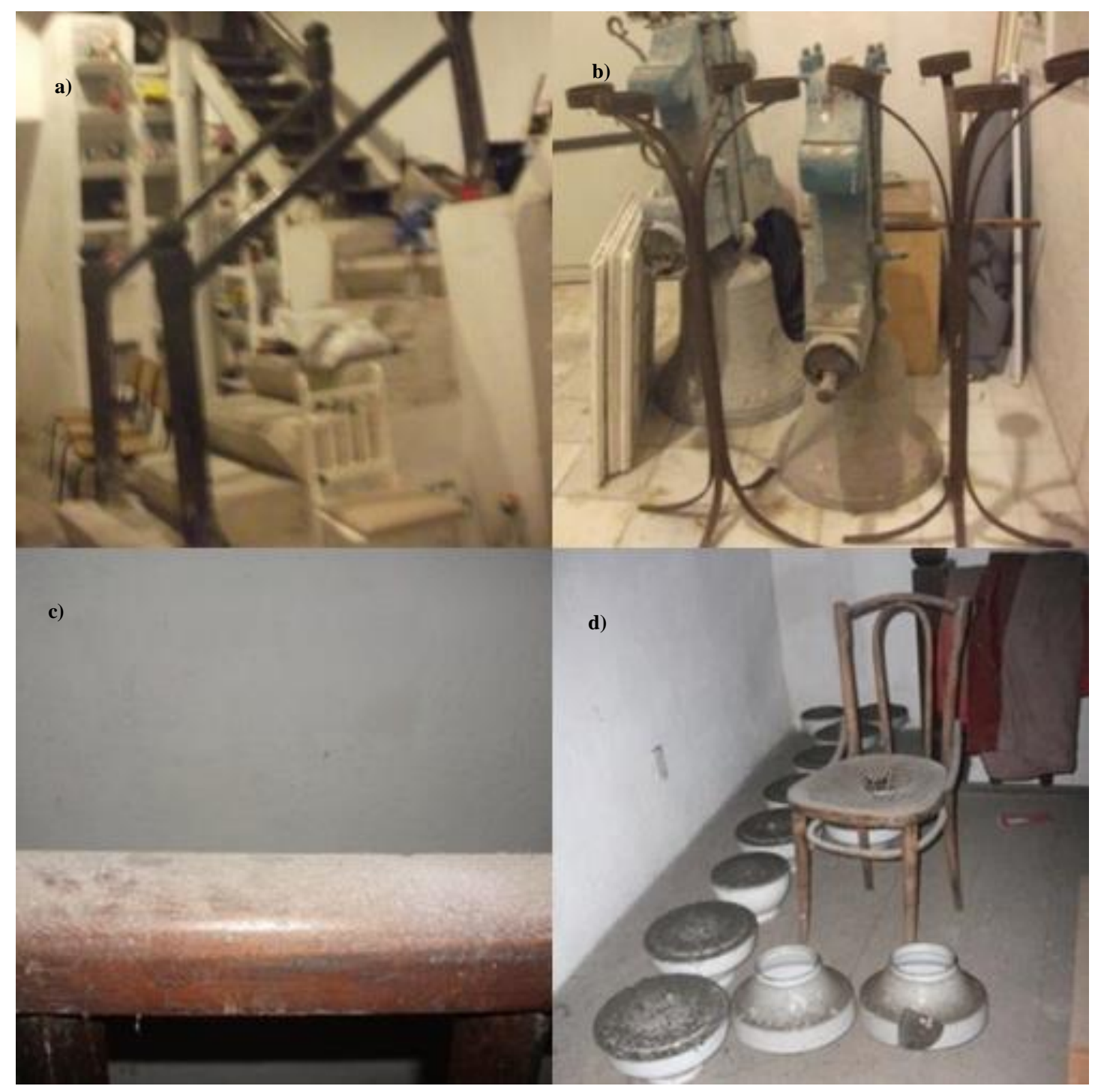

Figura 12: Espaços constituintes da igreja que estão em descaso. (a) Área dos jazigos em meio ao descaso e bagunça; (b) sinos e outros elementos históricos da igreja em abandono pelos corredores; (c) acúmulo excessivo de poeira nas escadarias; (d) acúmulo de poeira, descaso e abandono dos artefatos históricos pelos cômodos da igreja. Fonte: Acervo pessoal, 2018.

\section{Considerações Finais}

Neste trabalho, foram analisadas áreas associadas a aspectos históricos, físicos, administrativos e culturais, cuja restauração é fundamental para assegurar a conservação da memória deste monumento. No geral constata-se a crescente deterioração do patrimônio sacro e o quase nulo emprego de recursos humanos e financeiros destinados aos procedimentos de conservação, quase sempre se atenta à salvaguarda quando o bem já se 
encontra em estado avançado de degradação, necessitando de restauração, que é sempre uma ação invasiva e importuna.

A preservação do acervo depende de atitudes simples executadas por seu responsável, que deverá conhecê-lo para melhor preservá-lo. Observar, defender, respeitar e dar manutenção é o princípio básico da conservação, é necessário salientar por fim o dever de conservar para não restaurar e assim elevar os conhecimentos a gerações futuras.

A partir do levantamento históricos, foi constatado que a Igreja Madre de Deus, é possuidora de uma dimensão histórica cronologicamente extensa, desde sua criação até os dias atuais e também a partir do seu levantamento arquitetônico pode-se afirmar que ela é uma das mais belas, antigas e importantes igrejas do Recife, estando esta interligada a diversos monumentos nacionais e internacionais. Entretanto nas visitas à igreja se observou que esta é pouco explorada nos ambientes de ensino e pesquisa, consequentemente é pouco conhecida pela sociedade pernambucana.

Com isso, como emergencial considera-se importante propor um estudo aprofundado sobre a história da Madre de Deus. Esse estudo será a base para um projeto de educação patrimonial que irá promover o resgate do valor histórico da igreja para a sociedade e para guiar os profissionais envolvidos com a restauração e preservação do patrimônio histórico-cultural, reconhecido e ativo na memória coletiva da comunidade recifense.

Neste contexto, propõe-se também a volta do Circuito das Igrejas, um projeto dedicado a oferecer aos turistas e a população local um passeio pela arquitetura e história de Pernambuco, por meio de visitas a 11 igrejas pernambucanas construídas entre os séculos XVI, XVII e XVIII e tombadas pelo patrimônio histórico dos municípios de Recife, Olinda e Jaboatão dos Guararapes.

Outro fator que agregará a proposta é uma distribuição maior de folders virtuais, exposição em telas digitais e panfletos informativos sobre o circuito com foco no monumento em questão, nesse caso a Igreja da Madre de Deus. Junto a isso, nos corredores abaixo podem ser exibidos artefatos da igreja, contando sua história de forma guiada. Nas galerias superiores podem ser elaboradas atividades artístico-culturais para os visitantes envolvendo poesia local e música com o canto e com a exposição do órgão presente em estilo neoclássico, doado pelo Barão de Casa Forte, ainda na época da igreja do Corpo Santo. 


\section{Referências}

BARBOSA, A. Relíquias de Pernambuco: guia aos monumentos históricos de Olinda e Recife. Recife: Editora Fundo Educativo Brasileiro/BRAINTEC, 1983.

BAZAIN, G. Barroco e Rococó. São Paulo: Martins Fontes, 1993.

BRASIL Decreto Lei n²5, de 30 de novembro de 1937, da Constituição Brasileira.

LUSO, E.; LOURENÇO, P. B.; ALMEIDA, M. Breve história da teoria da conservação e do restauro. Engenharia Civil, Guimarães, n. 20, p. 31-44, 2004.

MELLO, E. C. D. A briga dos Néris. Estudos Avançados, Recife, 1994.

MENEZES, J. L. M. Recife - Igreja da Madre de Deus. Ipatrimonio, 2007. Disponivel em: http://www.ipatrimonio.org/recife-igreja-da-madre-de-deus/\#!/map=38329\&loc=8.064257000000008,-34.873919,17. Acesso em: 10 de abril 2020.

PRATES, A. E. et al. Restauração do patrimônio histórico cultural da Igreja Matriz de Nossa Senhora da Conceição e São José de Montes Claros - MG. Humanidades, São Paulo, v. 4, n. 1, Fevereiro 2015.

SALEMA, S.; PROENÇA, N.; CARDOSO, I. Conservation of the historical render in the Church of Nossa Senhora da Assunção in Elvas. Conservar Património, Évora, n. 8, p. 39-47, 2008.

SILVA, R. A. R. D.; FIGUEIREDO JÚNIOR, J. C. D. D.; SILVA, V. D. O. A conservação e preservação do patrimônio industrial: o caso do Rolo Compactador de Estrada a Vapor da Escola de Belas Artes/UFMG. IV Seminário Internacional Cultura Material e Patrimônio de C\&T. Rio de Janeiro, 2016.

SIMIS, T. C. Convento dos oratórianos de São Filipe de Néri: leituras arqueológicas de um convento que virou shopping em Recife-PE. Dissertação (Mestrado em Arqueologia), Universidade Federal de Pernambuco, Recife, 2005.

SMITH, R. C. Arquitetura colonial. Salvador: Cia. Progresso Editora, 1955.

SMITH, R. C. Igrejas, casas e móveis: aspectos de arte colonial brasileira. Recife: MEC/UFPE/IPHAN, 1979.

ZÁRATE, D. L.; MOREIRA, F. D. Conservação da autenticidade em centros históricos: um estudo sobre Polo Alfândega no Recife. CECI. Recife. 2010.

ZOLCZAK, E. Diagnóstico de Conservação: Modelo proposto para avaliar as necessidades do gerenciamento ambiental em museus. SISEM. São Paulo. 2013. 